\title{
UJI KEKERASAN KOMPOSIT TERHADAP RENDAMAN BUAH JERUK NIPIS (CITRUS AURANTIFOLIA)
}

\author{
${ }^{1}$ Patar Sitanggang \\ ${ }^{2}$ Elita Tambunan \\ ${ }^{3}$ Jane Wuisan
}

\author{
${ }^{1}$ Kandidat Skripsi Program Studi Pendidikan Dokter Gigi Fakultas Kedokteran \\ ${ }^{2}$ Program Studi Pendidikan Dokter Gigi Fakkultas Kedokteran \\ ${ }^{3}$ Universitas Sam Ratulangi Manado \\ E-mail: patar.sitanggang40@yahoo.com
}

\begin{abstract}
Lime (Citrus aurantifolia) contains an acid agent which can affects the surface hardness of composite. Change of surface hardness of composite is caused by infiltration of water containing the acid agent that affects the bonding of matrix to filler of composite.This study aimed to determine the effect of immersed lime on surface hardness of composite. This was an experimental laboratory study with a pre and post test control group design. The samples of resin composite had $5 \mathrm{~mm}$ in diameters and $4 \mathrm{~mm}$ in thickness $(\mathrm{n}=24)$. Samples were divided into two groups: mineral water as the control group and immersed lime as the trial group. Samples were alternately immersed for 30, 60, 120 minutes. Post immersion, the changes of composite hardness were measured with Mico Vickers Hardness Tester. Post immersion Vickers hardness was compared by using paired t-test. The result showed that immersed lime significantly reduced the surface hardness of composite $(\mathrm{p}<0.05)$. Duration of 60 and 120 minutes of lime immersion reduced significantly the surface hardness of composite $(p<0.05)$. It is suggested to reduce the duration of acidic fruit exposure such as lime to the composite.
\end{abstract}

Keywords: resin composite, surface hardness changes, lime

\begin{abstract}
Abstrak: Buah jeruk nipis (Citrus aurantifolia) mempunyai kandungan asa m yang dapat memengaruhi kekerasan komposit. Perubahan kekerasan komposit disebabkan oleh menyerapnya air yang mengandung asam pada komposit yang memengaruhi ikatan matriks dan filler. Penelitian ini bertujuan untuk mengetahui pengaruh perendaman buah jeruk nipis terhadap perubahan kekerasan komposit. Jenis penelitian ini ialah eksperimental laboratorium dengan desain pre and post test control group. Jumlah sampel penelitian ialah 24 resin komposit dengan diameter $5 \mathrm{~mm}$ dan tebal $4 \mathrm{~mm}$. Sampel dibagi menjadi 2 kelompok yaitu kelompok kontrol air mineral dan kelompok perlakuan yang direndam dalam sari jeruk nipis dengan 3 durasi waktu yang berbeda 30,60, dan 120 menit. Setelah perendaman diukur nilai perubahan kekerasan dengan Mico Vickers Hardness Tester. Hasil perendaman berdasarkan uji Vickers diuji banding secara statistik menggunakan uji paired sample $t$ test. Hasil penelitian menunjukkan adanya pengaruh perendaman buah jeruk nipis terhadap perubahan kekerasan komposit $(\mathrm{p}<0,05)$. Pada durasi waktu 60 dan 120 menit terdapat pengurangan yang bermakna dari kekerasan permukaan resin komposit $(p<0,05)$. Disarankan untuk mengurangi durasi paparan komposit terhadap buah-buahan yang mengandung asam seperti jeruk nipis.
\end{abstract}

Kata kunci: resin komposit, perubahan kekerasan permukaan, jeruk nipis

Indonesia termasuk negara kaya akan hasil pertanian salah satunya buah-buahan.
Jeruk nipis (citrus aurantifolia) merupakan buah-buahan yang banyak tumbuh dan 
dikembangkan di Indonesia. Jeruk nipis sering diolah masyarakat sebagai minuman segar seperti jus jeruk nipis, air jeruk nipis hangat dan minuman baru berbahan dasar jeruk nipis. $^{1}$

Buah jeruk nipis mempunyai kandungan yang bermanfaat seperti minyak atsiri, asam sitrat, asam amino. Kandungan asam pada jeruk nipis dapat menurunkan kekerasan permukaan resin komposit. ${ }^{2}$

Salah satu bahan tumpatan yang sering digunakan dalam kedokteran gigi ialah resin komposit. Resin komposit pertama diperkenalkan oleh Bowlen tahun 1962 dan digunakan awal 1970-an. Resin komposit merupakan bahan tumpatan sewarna gigi berupa gabungan dari dua atau lebih bahan kimia yang berbeda. ${ }^{2,3}$

Resin komposit mempunyai sifat fisik dan mekanik. Sifat fisik seperti penyerapan air, kelarutan dan konduktivitas. Sifat mekaniknya antara lain kekasaran permukaan, modulus elastisitas dan kekerasan. Kekerasan dapat digunakan sebagai alat ukur suatu bahan tumpatan untuk mengetahui kemampuan suatu bahan dalam menahan daya tekanan. Sifat kekerasan ini sangat dibutuhkan karena dapat mempengaruhi terhadap gesekan saat mengunyah makanan dan menyikat gigi. ${ }^{2,3}$

Ada beberapa faktor yang mempengaruhi kekerasan resin komposit diantaranya sifat fisik seperti kelarutan dan penyerapan air. Sifat kimiawi seperti kekerasan dipengaruhi oleh polimerisasi termasuk ketebalan dan lama penyinaran. Faktor lain yang mempengaruhi kekerasan komposit ialah makanan dan minuman yang dikomsumsi oleh pasien.,

Sifat fisik resin komposit seperti penyerapan air dan kelarutan akan meningkat apabila proses polimerisasi tidak optimal. Penyerapan air berawal dari minuman yang dikomsumsi pasien secara langsung berkontak dan merendam gigi. Minuman yang sering dikomsumsi masyarakat Indonesia ialah minuman yang mengandung asam seperti buah jeruk nipis. Meminum minuman yang mengandung asam secara terus menerus dan dalam waktu yang lama dapat mengerosi bahan tumpatan resin komposit. $^{3}$

\section{BAHAN DAN METODE PENELITIAN}

Penelitian ini bersifat eksperimental laboratorik dengan menggunakan rancangan pre and post test with control yang dilaksanakan di Laboratorium Teknik Mesin Fakultas Teknik Universitas Sam Ratulangi Manado pada bulan Februari 2015. Sampel penelitian ialah resin komposit yang berbentuk lingkaran dengan ukuran diameter $5 \mathrm{~mm}$ dan tinggi $4 \mathrm{~mm}$ sebanyak 24 buah. Pada penelitian ini digunakan beberapa variabel yaitu sari buah jeruk nipis sebagai variabel independen, kekerasan resin komposit sebagai variabel dependen, dan air mineral sebagai variabel kontrol.

Pembuatan sampel penelitian diawali dengan pembuatan cetakan sampel yang terbuat dari sedotan plastik, dilapisi vaselin dan diberi alas celluloid strip. Cetakan diletakkan di atas glass lab. Resin komposit yang berjumlah 18 dibentuk seperti lingkaran dengan ukuran diameter $5 \mathrm{~mm}$ dan tebal $4 \mathrm{~mm}$. Sampel dibagi menjadi 2 kelompok yaitu kelompok I terdiri dari 9 resin komposit untuk perendaman air mineral dan kelompok II terdiri dari 9 resin komposit untuk perendaman sari buah jeruk nipis. Masing-masing sampel diberi tanda nomor urut. Resin komposit diaplikasikan secara inkremental ke dalam cetakan yang telah siap menggunakan plastic filling instrument dengan tebal tiap lapisan $2 \mathrm{~mm}$. Bagian atas cetakan yang sudah terisi resin komposit ditutup dengan celluloid strip. Cetakan yang telah terisi resin komposit dilakukan penyinaran selama 40 detik. Resin komposit yang telah mengeras dilepas dari cetakan dengan menggunakan gagang kaca mulut. Resin komposit yang telah mengeras diukur kekerasan permukaan awal sebelum diberi perlakuan perendaman dengan Micro Vickers Hardness Tester.

Sari buah jeruk nipis dibuat dengan cara buah jeruk nipis dibelah menjadi dua bagian, bijinya dikeluarkan, diperas secara manual dan diukur derajat keasaman $(\mathrm{pH})$. Sari buah jeruk nipis yang diperlukan 
sebanyak $200 \mathrm{ml}$.

Perendaman kelompok I dan II dilakukan pada berbagai durasi waktu yaitu: durasi waktu 0 menit dengan 3 resin komposit, 30 menit dengan 3 resin komposit, 60 menit dengan 3 resin komposit, dan 120 menit dengan 3 resin komposit. Setiap kelompok dalam berbagai durasi waktu diukur kekerasannya dengan Micro Vickers Hardness Tester.

Hasil pengukuran kekerasan resin komposit dianalisis secara statistik dengan menggunakan program Statistical Product and Service Solution (SPSS). Data yang diperoleh diuji dengan analisis uji paired sample $t$ test dengan tingkat kepercayaan $95 \%(\alpha)=(0,05)$.

\section{HASIL PENELITIAN}

Tahap awal dari penelitian ini yaitu mengukur derajat keasaman $(\mathrm{pH})$ dari buah jeruk nipis dan air dalam kemasan yang hasilnya mempunyai $\mathrm{pH}$ 1,7 untuk buah jeruk nipis dan air dalam kemasan memiliki pH 7 kemudian dilakukan pembuatan sampel resin komposit berbentuk lingkaran dengan ukuran $5 \mathrm{~mm}$ dan tinggi $4 \mathrm{~mm}$ dan dilakukan pengukuran kekerasan komposit sebelum dan sesudah perendaman air mineral dan buah jeruk nipis menggunakan alat Micro Vickers Hardness Tester. Nilai rerata dan standar deviasi kekerasan resin komposit dapat dilihat pada tabel 1 .

Tabel 1. Nilai rerata dan standar deviasi kekerasan resin komposit (VHN)

\begin{tabular}{lccccc}
\hline Jenis Perendaman & $\mathrm{n}$ & \multicolumn{4}{c}{ Durasi waktu perendaman (menit) } \\
\cline { 3 - 6 }$\overline{\boldsymbol{x}} \pm \mathrm{SD}$ & & Sebelum & & Sesudah & \\
& & 0 & $30(\mathrm{a})$ & $60(\mathrm{~b})$ & $120(\mathrm{c})$ \\
Air Mineral (Kelompok I) & 3 & 60.90 & 59.43 & 59.43 & 59.43 \\
& & \pm 0.0 & \pm 0.94 & \pm 0.94 & \pm 0.94 \\
Jeruk Nipis (Kelompok II) & 3 & 60.80 & 54.46 & 46.80 & 29.46 \\
& & \pm 0.0 & \pm 10.38 & \pm 4.10 & \pm 8.86 \\
\hline
\end{tabular}

$\mathrm{n}=$ jumlah sampel, $\bar{x}=$ rerata kekerasan komposit $\mathrm{SD}=$ Standar deviasi

Perendaman pada air mineral tidak terdapat perbedan nilai rerata kekerasan sesudah perendaman $(30,60$ dan 120 menit).Pada jeruk nipis terdapat perbedaan nilai rerata sesudah perendaman (30, 60 dan 120 menit).

Data hasil penelitian ini dibagi menjadi dua kelompok untuk mempermudah dalam menganalisis data. Kelompok I air mineral dan kelompok II sari jeruk nipis, dengan pembagiannya yaitu kelompok Ia (sesudah perendaman air mineral 30 menit), Ib (sesudah perendaman air mineral 60 menit), Ic (sesudah perendaman air mineral 120 menit), selanjutnya di kelompok IIa (sesudah perendaman sari jeruk nipis 30 menit), IIb (sesudah perendaman sari jeruk nipis 60 menit), IIc (sesudah perendaman sari jeruk nipis 120 menit).

Hasil statistika melalui uji normalitas menyatakan bahwa data yang ada terdistribusi normal dengan nilai $\mathrm{p}>0,05$. Setelah diketahui semua kelompok data mempunyai distribusi normal, maka untuk mengetahui perbedaan bermakna kekerasan resin komposit terhadap buah jeruk nipis, dilakukan uji parametik paired sample t test dengan nilai $\mathrm{p}<0,05$. Uji paired sample $\mathrm{t}$ test ialah uji statistik berpasangan antara dua variabel sebelum dan sesudah perendaman dengan menunjukan data berdistribusi normal $(\mathrm{p}>0,05)$ dan tidak perlu dilakukan uji homogenitas.

Uji paired sample $t$ test hanya dilakukan pada perendaman sari jeruk nipis (kelompok II) karena pada perendaman air mineral tidak ada perbedaan nilai kekerasannya. Uji dilakukan untuk melihat ada perbedaan yang bermakna antara sebelum dan sesudah perendaman. 
Sitanggang, Tambunan, Wuisan: Uji kekerasan komposit terhadap rendaman ...

Tabel 2.Hasil Uji Paired sample t test pada buah jeruk nipis

\begin{tabular}{lcccc}
\hline & $\mathrm{n}$ & \multicolumn{3}{c}{ Sesudah Perendaman } \\
$\begin{array}{c}\text { Sebelum } \\
\text { Perendaman }\end{array}$ & & Kel.IIa & Kel.IIb & Kel.IIc \\
Kel.II & 3 & 30 menit & 60 menit & 120 menit \\
& & $p$ & $p$ & $p$ \\
& & 0,396 & 0,027 & 0,025 \\
\hline
\end{tabular}

Hasil paired sample t test pada tabel 2 menunjukkan nilai probabilitas dari kelompok waktu 30 menit $(\mathrm{p}>0,05)$ memiliki arti bahwa nilai kekerasan sebelum dan sesudah perendaman sari jeruk nipis tidak ada perbedaan yang bermakna. Kelompok waktu 60 menit dan 120 menit $(\mathrm{p}<0,05)$ memiliki arti bahwa nilai kekerasan sebelum dan sesudah perendaman sari jeruk nipis terdapat perbedaan yang bermakna.

\section{BAHASAN}

Pemilihan lama waktu perendaman 30 menit, 60 menit, dan 120 menit pada penelitian ini didasarkan pada 30 menit yaitu estimasi jumlah lama waktu terpaparnya komposit dengan minuman yang dikonsumsi dalam setiap gelas/hari (1 menit) selama 30 hari sehingga estimasi total jumlah waktu yang dibutuhkan ketika mengkonsumsi minuman selama 1 bulan, 2 bulan, dan 4 bulan yaitu30 menit, 60 menit, dan 120 menit.

Hasil pengujian pada tabel 1 dan 2 menunjukan tidak terdapat penurunan kekerasan komposit pada perendaman air pada waktu 30, 60 dan 120 menit. Keadaan ini disebabkan oleh $\mathrm{pH}$ air dalam kemasan netral ialah 7. Nilai $\mathrm{pH}$ tersebut menunjukan larutan tidak bersifat asam sehingga komposit tidak terjadi proses polimerisasi.

Pada perendaman air jeruk nipis terdapat penurunan kekerasan komposit pada perendaman buah jeruk nipis pada waktu 30, 60 dan 120 menit. Perbedaan penurunan kekerasan pada 30 menit tidak bermakna $\mathrm{p}=0,396$. Penurunan yang bermakna hanya terdapat pada waktu 60 menit nilai $\mathrm{p}=0,027$ dan waktu 120 menit nilai $\mathrm{p}=0,025(\mathrm{p}<0,05)$.

Pada penelitian ini komposit terus mengalami penurunan kekerasaan dari waktu ke waktu, dalam hal ini komposit belum mencapai titik jenuh nya. Sebelum mencapai titik jenuhnya komposit akan terus mengalami penurunan kekerasan, hal ini disebabkan oleh adanya ruang intermolekular yang kosong dan masih diisi oleh air. Air akan terus mengisi ruang tersebut sampai tidak ada lagi ruang yang dapat dimasuki air. Pada keadaan ini komposit akan mencapai titik jenuh, nilai kekerasaan tidak akan mengalami penurunan dan akan stabil.

Penelitian yang dilakukan oleh Mckenzie et al. pada tahun 2004 tentang efek coca-cola dan jus buah terhadap kekerasan permukaan dari ionomer kaca dan kompomer menyatakan bahwa terjadinya penurunan resin komposit yang signifikan setelah perendaman coca-cola selama 1 hari, 1 bulan, 3 bulan, 4 bulan, dan 6 bulan. ${ }^{4}$ Penelitian lain juga dilakukan oleh Yanikoglu et al. pada tahun 2009 tentang efek dari perbedaan campuran pada permukaan kekerasan dari material resin menyatakan bahwa perendaman minuman cola selama 24 jam yang mengandung asam dapat mempengaruhi kekerasan yang signifikan terhadap bahan restorasi resin komposit. $^{5}$ Dua penelitian diatas memperkuat hasil penelitian bahwa kandungan asam yang sama tetapi mempunyai perbedaan durasi dapat mendegradasi bahan tumpatan komposit. ${ }^{2}$

Penelitian yang dilakukan Hengtrakool 
C et al. pada tahun 2011 tentang efek dari kekerasan mikro dan permukaan mikro morfologi dari material tumpatan menyatakan bahwa kandungan asam pada buah yang memiliki $\mathrm{pH}$ rendah dapat menurunkan kekerasan komposit. Penelitian ini menggunakan buah-buahan yang diolah seperti jus manga dan jus nenas yang memiliki kandungan asam yang dapat mengerosi enamel dan komposit. ${ }^{6}$

Penelitian lain yang dilakukan oleh Poggio et al. pada tahun 2012 tentang kekasaran permukaan dari resin komposit tipe flowable yang mengerosi akibat minuman asam dan mengandung alcohol menyatakan bahwa keterpaparan terhadap asam dalam berbagai derajat keadaan asam yang berbeda sangat berpengaruh terhadap penurunan komposisi, kekerasan dan kekasaran dari resin komposit. ${ }^{7}$

Proses penurunan kekerasan permukaan komposit akibat tingkat keasaman dilaporkan juga oleh Valinoti et al. pada tahun 2008 dan Narsimha pada tahun 2011. Penelitian Valinoti mengungkapkan bahwa resin komposit berbagai merek mengalami penurunan kekerasan akibat kandungan $\mathrm{pH}$ yang berada dalam suasana asam dan penelitian Narsimha mengungkapkan bahwa efek cola yang memiliki kandungan asam dapat menurunkan kekerasan permukaan berbagai material tumpatan seperti resin modifikasi glas ionomer dan resin komposit. ${ }^{8,9}$

Penurunan kekerasan permukaan komposit diakibatkan adanya sifat penyerapan air pada komposit. Air yang mengandung asam dapat diserap komposit sehingga merusak ikatan matriks dan filler. Terganggunya ikatan matriks dan filler mengakibatkan terbentuknya monomer sisa metil metalkrilat. ${ }^{2}$

Monomer sisa akan terlepas dari komposit apabila menyentuh cairan rongga mulut atau cairan yang mengandung asam. Asam memiliki banyak ion $\mathrm{H}^{+}$yang berdifusi kedalam matriks kemudian mengikat ion negatif yang ada didalam matriks. Ion $\mathrm{H}^{+}$mempengaruhi ion lainnya terdorong keluar dan bebas pada matriks. Hilangnya ion pada matriks mengakibatkan kandungan asam natural terhadap putusnya ikatan kimia menjadi tidak stabil sehingga matriks juga larut dan terurai. ${ }^{10}$

\section{SIMPULAN}

Perubahan kekerasan komposit terhadap perendaman buah jeruk nipis tidak terjadi pada durasi waktu 30 menit tetapi pada durasi waktu 60 dan 120 menit.

\section{SARAN}

Saat mengonsumsi makanan atau minuman yang mengandung asam diharapkan untuk mengurangi durasi kontak terhadap gigi dan mulut dengan cara memakai alat bantuan penghisap seperti sedotan, atau berkumur setelah makan atau minum yang mengandung asam.

Perlunya penelitian lebih lanjut tentang bahan tambalan gigi yang kekerasaannya tidak terpengaruh oleh buah-buahan yang mengandung asam.

\section{DAFTAR PUSTAKA}

1. Hariana HA. Tumbuhan Obat dan Khasiatnya. Jakarta: Niaga swadaya, 2008; p. 149-52.

2. Wongkhantee S, Patanapiradej V, Maneenut C, Tantbirojn. Effect of acidic food and drinks on surface hardness of enamel, dentine, and toothcoloured filling materials. J Dentistry 2005; 20:1-7.

3. Han L, Okamoto A, Fukushima M, Okiji T. Evaluation of flowable resin composite surfaces eroded by acidic and alcoholic drinks. Dent mater J. 2008; 455-65.

4. Mckenzie MA, Linden RWA, Nicholson JW. The effect of cocacola and fruit juices on the surface hardness of glass-ionomer and compomers. J Oral Rehabilitation. 2004;31:1046-52.

5. Yanikoglu N, Duymus ZY, Yilmaz B. Effect of different solution on the surface hardness of resin materials. DentalMater J. 2009;28(3):344-51.

\section{Hengtrakool C, Kukiattrakoon B,} Kedjarune-Leghgal $U$. Effect of naturally acidic agent on microhardness and surface micromorphology of 
restorative materials. Euoropean Journal of Dentistry 2011;5:89-100.

7. Poggio C, Dagna A, Chiesa M, Colombo M, Scribante A. Surface roughness of flowable rsin composites eroded by acidic and alcoholic drinks. Journal of conservative dentistry 2012;15(2):13739.

8. Valinoti AC, Neves BG, Silva EM, Maia LC. Surface degradation of composite resin by acidic medicines and $\mathrm{pH}-$ cycling. Journal of apllied oral science 2008;16(4):257-65.
9. Narsimha VV. Effect cola on surface microhardness and marginal integrity of resin modified glass ionomer and compomer restoration - an in vitro study. People's journal of scientific research. 2011;4(2):34-40.

10. Aguiar FHB, Andrade KRM, Lima DAL, Ambrosano GMB, Lovadino JR. Influence of light curing and sampel thickness on microhardness of a composite resin. Clinical Cosmetic Investigation Dentistry. 2009;1:21-5. 